Review Article

www.ijrap.net

\title{
UNANI DRUGS IN THE MANAGEMENT OF CARDIOVASCULAR DISEASES: A REVIEW ON PHARMACOLOGICAL STUDIES ON ARJUN AND ZAFRAN
}

\author{
Rabbani Syed Arman*1, Ali Syed Mahtab
${ }^{1}$ Ph.D Scholar, Department of Pharmaceutical Medicine, Jamia Hamdard, New Delhi, India
}

${ }^{2}$ Dean, Faculty of Unani Medicine, Jamia Hamdard, New Delhi, India

Received on: 09/01/13 Revised on: 22/02/13 Accepted on: 10/03/13

\begin{abstract}
*Corresponding author
E-mail: smali@jamiahamdard.ac.in

DOI: $10.7897 / 2277-4343.04332$

Published by Moksha Publishing House. Website www.mokshaph.com

All rights reserved.
\end{abstract}

\section{ABSTRACT}

Cardiovascular diseases (CVDs) are the leading cause of death and disability in the world. They have emerged as a major health threat in developing countries contrary to the prior belief that they were confined primarily to industrialized nations. The global burden of disease due to cardiovascular diseases is escalating, principally due to a sharp rise in the developing countries which are experiencing rapid health transition. An estimated 17.3 million people died from CVDs in 2008 and over $80 \%$ of CVD deaths take place in low and middle income countries. By 2030 , almost 23.6 million people will die from CVDs. Therefore, finding ways to reduce the mortality of cardiovascular disease remains an important public health goal. Traditional Medicines have been an integral part of the healthcare system since time immemorial. WHO reports indicate that around eighty percent of the global population still relies on botanical drugs and several herbal medicines have advanced to clinical use in modern times. Unani occupies an important place in the rich traditional heritage of indigenous systems of medicine in India and contributes significantly to the health care. The core of treatment in Unani System of Medicine is based on drugs of herbal, mineral and animal origin. The ancient classical literature of Unani has mention of numerous drugs possessing cardioprotective and cardiotonic activity, Arjun (Terminalia arjuna) and Zafran (Crocus sativus) are two of them. The Unani physicians have been using these drugs successfully since ages and this is possible only by inherent quality and safety standards specified in the system.

With the advent of new techniques and recent upsurge towards scientific exploration of traditional medicines, empirical data substantiating their safety and efficacy has been generated and had led to better understanding of their role to prevent and cure diseases. The aim of this paper is to review and highlight the work done on Arjun (Terminalia arjuna) and Zafran (Crocus sativus) as cardioprotectives and cardiotonics mentioned in Unani literature as well as highlight the scientific exploration of the same.

Keywords: Cardiovascular diseases; Unani; Arjun; Zafran; Cardioprotective; Cardiotonics

\section{INTRODUCTION}

Cardiovascular diseases (CVDs) are the leading cause of death worldwide and deaths due to CVDs are projected to increase from 17.3 million in 2008 to 23.6 million in 2030. According to WHO, ischaemic heart disease and cerebrovascular disease (stroke) are amongst the projected leading causes of death globally in 2030. ${ }^{1}$ The global burden of disease due to CVDs is escalating, principally due to a sharp rise in the developing countries which are experiencing rapid health transition. ${ }^{2}$

Cardiovascular disease strikes Indians early and kills many in their productive mid-life years. The reported prevalence of CVDs in adult surveys has risen 4-fold over the last 40 years, and even in rural areas the prevalence has doubled over the past 30 years. Indians appear to manifest high risk of CVDs when the undefined factors that contribute to ethnic susceptibility are triggered or magnified by an environment that promotes unhealthy living habits and superimposes conventional risk factors. ${ }^{3}$ The World Health Organization (WHO) estimates that $80 \%$ of the people of developing countries rely on traditional medicines, mostly plant-derived drugs, for their primary health needs. Medicinal plants are commonly used in treating and preventing specific ailments and are considered to play a significant role in health care. Traditional medicinal systems use plants as indispensable sources of medicinal preparations.
Hundreds of species are recognized as having medicinal value. Indeed, 'phytomedicines' are beginning to link traditional and modern medicines. ${ }^{4}$ For cardiovascular diseases, herbal treatments have been used in patients with congestive heart failure, systolic hypertension, angina pectoris, atherosclerosis, cerebral insufficiency, venous insufficiency and arrhythmia. ${ }^{5}$

India has a very long, safe and continuous usage of many herbal drugs in the officially recognized alternative systems of health viz. Ayurveda, Yoga, Unani, Siddha, Homeopathy and Naturopathy. ${ }^{6,7}$

According to the Unani system of Medicine, heart occupies a very significant place as it is one of Aza- eRaisa (vital organs), which are the source of primary faculties in the body, and are indispensable for the existence of the individual. ${ }^{8}$ There is a large collection of single herbs as well as poly herbal formulations documented in the classical texts for cardiovascular disorders acting as Muqavvi Qalb (cardiotonics), Mufarreh, Muqavvi Aza-e- Raisa (Vital organ tonic) etc. In this review, an attempt has been made to focus on the cardioprotective and cardiotonic effects of Arjun (Terminalia arjuna) and Zafran (Crocus sativus) and provide scientific account of use of these time-tested drugs based on their pharmacological activities reported in various research and review papers. 


\section{ARJUN (Terminalia arjuna)}

\section{Parts used}

Stem bark, Fruit, Leaf, Bark, Ashes.

\section{Actions}

Stem bark: tonic, astringent, febrifuge.

Fruit: tonic, expectorant.

\section{Uses}

Stem bark: heart diseases as cardiac tonic, in bilious affection, sores.

Fresh leaf juice: ear ache.

Fruit: cough, sore throat, dyspepsia ${ }^{9}$

\section{Chemical constituents}

Terminalia's active constituents include tannins, triterpenoid saponins (arjunic acid, arjunolic acid, arjungenin, arjunglycosides), flavonoids (arjunone, arjunolone, luteolin), gallic acid, ellagic acid, oligomeric proanthocyanidins (OPCs), phytosterols, calcium, magnesium, zinc, and copper. ${ }^{10}$

\section{Mechanisms of Action}

Terminalia arjuna bark contains a very high level of flavonoids. Flavonoids detected from its bark are namely, arjunolone, flavones, bicalein, quercetin, kempferol and pelorgonidin. There is enough convincing evidence that bioflavonoids, by virtue of their free radical scavenging action, prevent oxidation of LDL cholesterol, enhance endothelial derived nitric oxide activity, inhibit endothelial activation and inhibit platelet aggregation. They possibly also inhibit cyclooxygenases and reduce the risk of thrombosis. High intake of dietary flavonoids is considered to be inversely related to the risk of Coronary Artery Disease (CAD). A high flavonoid content of Terminalia arjuna, may possibly account for its beneficial effects in CAD.

In addition to flavonoids, a variety of tannins have been isolated from the bark of Terminalia arjuna. Tannins are known to enhance synthesis of nitric oxide and relax vascular segments precontracted with norepinephrine. It may well be that tannins may be contributing to the reported hypotensive action of Terminalia arjuna bark. ${ }^{11}$ It is thought that the saponin glycosides might be responsible for the inotropic effect of Terminalia arjuna, while the flavonoids and OPCs provide free radical antioxidant activity and vascular strengthening. Recently, two new cardenolide cardiac glycosides were isolated from the root and seed of Terminalia arjuna. The main action of these cardenolides is to increase the force of cardiac contraction by means of a rise in both intracellular sodium and calcium. ${ }^{10}$

\section{Pharmacological activities related to CVS Cardioprotective and antioxidant activities}

Over the past several years, significant experimental data have emerged suggesting a role for increased reactive oxygen species (ROS) in the pathophysiology of Congestive Heart Failure (CHF). ROS plays an important role in the development and progression of heart failure, regardless of the aetiology. ${ }^{12}$ The cardioprotective effects of arjuna are partly related to its antioxidant activities and several studies have shown arjuna to protect the heart against myocardial ischemic reperfusion injury. ${ }^{14}$

Effect of arjunolic acid derived from Terminalia arjuna (15 $\mathrm{mg} / \mathrm{kg}$ body weight) on antiplatelet activity, electrocardiographic changes, serum marker enzymes, antioxidant status, lipid peroxide and myeloperoxidase (MPO) were measured and compared with the acetyl salicylic acid (ASA) in rats subjected to isoproterenol challenge. The drug was given intraperitoneally before and after isoproterenol administration. Arjunolic acid treatment prevented the decrease in the levels of super oxide dismutase (SOD), catalase (CAT), glutathione peroxidase, ceruloplasmin, $\alpha$-tocopherol, reduced glutathione (GSH), ascorbic acid, lipid peroxide and MPO. These observations were corroborated by histopathological studies. Cardioprotection conferred by arjunolic acid could possibly be due to the protective effect against the damage caused by myocardial necrosis. $^{11}$

The result of a study to determine the role of Terminalia arjuna as an antioxidant agent on ischemic perfused rat heart suggested that administration of dried pulverized bark of TA orally to Wistar albino rats augments endogenous antioxidant compounds (SOD, GSH and CAT) of rat heart and also prevents oxidative stress associated with ischemic-reperfusion injury of the heart. ${ }^{14}$

Another study designed to investigate the effects of chronic administration of the alcoholic extract of Terminalia arjuna bark on isoproterenol induced myocardial injury demonstrated that the $6.75 \mathrm{mg} / \mathrm{kg}$ of the drug augments endogenous antioxidant compounds (GSH, SOD, and catalase) of the rat heart and also prevents the myocardium from isoproterenol induced myocardial ischemic reperfusion injury. ${ }^{15}$

In another study effect of a compound formulation (abana) containing Terminalia arjuna $30 \mathrm{mg}$ per tablet, was studied in isoproterenol-induced myocardial necrosis in rats. Increase in serum CPK, SGOT, SGPT and Y-GT following myocardial necrosis were significantly reversed by abana.

Arjungenin, an oleanane terpenoid derived from Terminalia arjuna bark and its glucoside, arjunglucoside II, have been demonstrated to exert free radical scavenging activities in human polymorphonuclear cells. $^{11}$

The results of a study designed to investigate the cardioprotective role of chronic oral administration of alcoholic extract of bark powder of Terminalia arjuna in in-vivo ischemic reperfusion injury and the induction of heat shock protein (HSP) 72 in rabbit showed that it induces myocardial HSP 72 and augments myocardial endogenous antioxidants, without causing any cellular injury and offered better cardioprotection against oxidative stress associated with myocardial IR injury. ${ }^{16}$

One of the studies demonstrated that the aqueous extract of the bark of Terminalia arjuna could protect the liver and kidney tissues against CCl4 (carbon tetrachloride) induced oxidative stress probably by increasing antioxidative defense activities. ${ }^{17}$ 


\section{Hypotensive actions}

Several earlier studies in rats and dogs had demonstrated the hypotensive effects of Terminalia arjuna. ${ }^{11}$ Recently, in a study the effect of $70 \%$ alcoholic extract of Terminalia arjuna on anaesthetized dog blood pressure was studied and Intravenous administration of Terminalia arjuna produced dose-dependent hypotension in anaesthetized dogs and suggested likely involvement of peripheral mechanism for hypotension. The hypotension produced by $6 \mathrm{mg} / \mathrm{kg}$ dose of the extract was blocked by propranolol but not by atropine or mepyramine maleate indicating that muscarinic or histaminergic mechanisms are not likely to be involved in the hypotension produced by the extract. The blockade by propranolol of the hypotension produced by Terminalia arjuna indicated that the extract might contain active compound(s) possessing adrenergic $\beta 2$-receptor agonist action and or that act directly on the heart muscle. ${ }^{18}$

\section{Effects on lipids}

A $50 \%$ ethanol extract of Terminalia arjuna significantly lowered total and LDL cholesterol and improved the LDL to HDL ratio in diet-induced hyperlipidaemic rabbits.

Terminalia arjuna has also shown to have reduced lipids and development of atheroma in rabbits on a high cholesterol diet.

An Ayurvedic formulation containing methanolic extracts of selected parts of plants Commiphora mukul, Allium sativum, Plumbago indica, Semecarpus anacardium, Hemidesmus indicus, Terminalia arjuna, Tinospora cordifolia, Withania somnifera and Ocimum sanctum was found to scavenge superoxide and hydroxyl radicals in vitro and significantly $(\mathrm{p}<0.001)$ inhibit lipid peroxidation, delay plasma recalcification and enhance the release of lipoprotein lipase enzyme in vivo.

The formulation also inhibited chemically-induced platelet aggregation in vitro, which was comparable to heparin. The anti-inflammatory action of the formulation was significant $(\mathrm{p}<0.001)$ with acute and chronic inflammations induced by carrageenan and formalin respectively in rats. The formulation furthermore significantly reduced blood lipids $(p<0.001)$ and improved HDL in diet-induced hyperlipidaemia in rats over a period of 30 days. $^{13}$

\section{Clinical studies related to CVS Congestive Heart Failure}

Several studies have confirmed its decongestive effect and shown improvement in echo- Left ventricular ejection fraction (LVEF); improvement in exercise duration, significant reduction in heart size as well as improvement in symptoms, signs, effort tolerance, with improvement in quality of life. ${ }^{11}$ A double-blind, placebo-controlled, twophase trial of Terminalia arjuna extract in 12 patients with severe refractory heart failure (New York Heart Association, NYHA Class IV) was conducted, in which either $500 \mathrm{mg}$ Terminalia bark extract or placebo was given every eight hours for two weeks, in addition to the patients' current pharmaceutical medications (digoxin, diuretics, angiotensin-converting enzyme inhibitors, vasodilators, and potassium supplementation). All patients experienced dyspnea at rest or after minimal activity at the start of the trial. Dyspnea, fatigue, edema, and walking tolerance all improved while patients were on Terminalia arjuna therapy. Treatment with Terminalia arjuna was also associated with significant improvements in stroke volume and left ventricular ejection fraction, as well as decreases in end-diastolic and end-systolic left ventricular volumes compared to placebo. In the second phase of the study, patients from phase I continued on Terminalia extract for two years. Improvements were noted in the ensuing 2-3 months, and were maintained through the balance of the study. After four months' treatment, nine patients improved to NYHA Class II and three improved to NYHA Class III.

\section{Ischemic Heart Disease}

The utility of Terminalia arjuna therapy in ischemic stroke and ischemic heart disease has been extensively studied by several group of workers ${ }^{11}$ which established its anti ischemic potential.

Fifty-eight males with chronic stable angina (NYHA class II-III) with evidence of provocable ischemia on treadmill exercise test received Terminalia arjuna (500 $\mathrm{mg} 8$ hourly), isosorbide mononitrate (40 mg/daily) or a matching placebo for one week each, separated by a wash-out period of at least three days in a randomized, double-blind, crossover design. They underwent clinical, biochemical and treadmill exercise evaluation at the end of each therapy which were compared during the three therapy periods. Terminalia arjuna bark extract, $500 \mathrm{mg} 8$ hourly, given to patients with stable angina with provocable ischemia on treadmill exercise, led to improvement in clinical and treadmill exercise parameters as compared to placebo therapy. These benefits were similar to those observed with isosorbide mononitrate (40 $\mathrm{mg}$ /day) therapy and the extract was well tolerated. No significant untoward effects were reported during Terminalia arjuna therapy. ${ }^{19}$

\section{Hypercholesterolaemia}

Arjun tree bark powder has significant antioxidant action that is comparable to vitamin E. In addition, it also has a significant hypocholesterolaemic effect. In a study, one hundred and five patients with coronary heart disease (CHD) were divided into 3 groups of 35 each. The groups were matched for age, lifestyle and dietary variables, clinical diagnosis and drug treatment status. None of the patients was on lipid-lowering drugs. Supplemental vitamins were stopped for one month before study and American Heart Association step II dietary advice was given to all. Group I received placebo capsules; Group II vitamin E capsules 400 units/day; and Group III received finely pulverised arjuna tree bark-powder $(500 \mathrm{mg})$ in capsules daily. Response rate in various groups varied from $86 \%$ to $91 \%$. Neither Vitamin E nor placebo caused any significant changes in total, HDL, LDL cholesterol and triglycerides levels (paired t-test $\mathrm{p}>0.05$ ). In the arjuna treated group, however, there was a significant decrease in total cholesterol $(-9.7+/-12.7 \%)$, and LDL cholesterol $(-15.8+/-25.6 \%)$ (paired t-test $\mathrm{p}<0.01)$. Vitamin $\mathrm{E}$ and arjuna both decreased lipid peroxide levels significantly $(\mathrm{p}<0.01)$. 
A study describes that arjuna bark powder along with statin for 3 months resulted in $15 \%$ decrease in total cholesterol, $11 \%$ in triglycerides and $16 \%$ in LDLcholesterol. There was minimal decline in lipoprotein and nitrite levels. The results suggest that arjuna may work synergistically with statin in hyperlipidaemia. ${ }^{13}$

\section{ZAFRAN (Crocus sativus)}

Crocus sativus is a flowering plant in the crocus family and is commonly known as zafran or saffron. It is widely used as spice and as a coloring and flavoring agent in the preparation of various foods and cosmetics. It is native to Iran and Greece. The stigmas of the plant are mainly used for therapeutic purposes. It is used as an aphrodisiac, antispasmodic and expectorant. It is also used to treat insomnia dysentery, jaundice, and cholera. It is considered as a tonic for heart and nervous system.

\section{Chemical constituents}

Chemical studies on Crocus sativus stigmas reported that it possesses carotenoids like crocetin (also called $\alpha$-crocetin or crocetin-I); its glycosidic forms are digentiobioside (crocin), gentiobioside, glucoside, gentioglucoside and diglucoside.

The monoterpene aldehydes picrocrocin and its deglycosylated derivative safranal (dehydro- $\beta$-cyclocitral), formed in saffron during drying and storage by the hydrolysis of the picrocrocin, are also important components of saffron, responsible of its bitter flavour and aroma, respectively.

Anthocyanins, flavonoids, vitamins (especially riboflavin and thiamine), amino acids, proteins, starch, mineral matter, gums and other chemical compounds presence were also described in saffron. Among the constituents of saffron extract crocin is mainly responsible for its pharmacological activities. $^{20}$

\section{Mechanism of action}

Crocin scavenge free radicals, especially superoxide anions, and so may protect cells from oxidative stress. Crocin is useful as sperm cryoconservation and in protecting hepatocytes from toxins. Because of its powerful antioxidant activity, it could be useful in the therapy of neurodegenerative disorders. ${ }^{21}$

Its antioxidant property is due to its secondary metabolites and their derivatives (safranal, crocetin, dimethyl crocetin). The antioxidant activity of saffron carotenoids is more effective than safranal. However the synergistic effect of all the bioactive constituents gives to saffron spice a significant antioxidant activity. The antioxidant activity of saffron compounds can protect DNA and tRNA from harmful chemical reaction in this ligandpolynucleotide complex. $^{22}$

\section{Pharmacological Activities Hypolipidemic activity}

Crocin, one of the constituents of saffron was shown to produce hypolipidemic effect in the dose range of $25 \mathrm{mg} / \mathrm{kg}$ to $100 \mathrm{mg} / \mathrm{kg}$ body weight in diet-induced hyperlipidemic rats by inhibiting pancreatic lipase thereby leading to mal absorption of fat and cholesterol producing hypolipidemic effect. ${ }^{20}$

\section{Cardioprotection}

Crocetin, the main active constituent of saffron was found to decrease the level of cardiac marker - lactate dehydrogenase activity and also increase mitochondrion potential in a cardiac myocyte treated with noradrenaline, suggesting its cardioprotective action.

Saffron was also showed to possess calcium antagonistic activity. This antagonistic activity was through the blockade of extracellular $\mathrm{Ca}(2+)$ influx through receptor-operated $\mathrm{Ca}(2+)$ channels and potential-dependent $\mathrm{Ca}(2+)$ channels.

In another study, crocetin by virtue of its strong antioxidant activity prevented the cardiac hypertrophy induced by norepinephrine by increasing the levels of the antioxidant enzymes such as myocardial superoxide dismutase, catalase, glutathione peroxidase and also significantly improved the myocardial pathological histological changes induced by norepinephrine. ${ }^{20}$

The effects of oral administration of crocin in rats $(5,10$ and $20 \mathrm{mg} / \mathrm{kg} /$ day), was investigated in isoproterenol (ISO)-induced cardiotoxicity with reference to hemodynamic, antioxidant, histopathological and ultra structural parameters. Crocin at the dose of $20 \mathrm{mg} / \mathrm{kg} /$ day significantly modulated hemodynamic and antioxidant derangements. The preventive role of crocin on ISOinduced Myocardial Infarction (MI) was reconfirmed by histopathological and ultra structural examinations. The effect at the dose of $20 \mathrm{mg} / \mathrm{kg} /$ day of crocin was more pronounced than that of other two doses (5 and $10 \mathrm{mg} / \mathrm{kg} /$ day). The results suggested that crocin may have cardio protective effect in ISO-induced cardiac toxicity through modulation of oxidative stress in such a way that maintains the redox status of the cell. ${ }^{23}$

Another study investigated the effects of crocin, on cardiac reperfusion-induced arrhythmia and antioxidant systems (catalase, superoxide dismutase (SOD), glutathione (GSH) and malondialdehyde (MDA, as a marker of lipid peroxidation) levels in rats. The results suggested that crocin is partially capable of suppressing reperfusion-induced arrhythmias and exhibhited protective role of crocin on cardiac reperfusion arrhythmias which may at least partially be related to stability or even amplification of antioxidant systems. ${ }^{24}$

\section{Crocin in the treatment of atherosclerosis}

Adhesion and migration of the leukocyte to endothelial cells is one of the early key steps in the pathogenesis of atherosclerosis and advance glycation end products (AGEs) promote this migration possibly by the expression of the intercellular adhesion molecule-1 (ICAM-1) protein. Crocetin (a metabolite of crocin) could inhibit AGE induced bovine endothelial cells (BEC) growth suppression and significantly reduce the adhesion rate of leukocyte to BEC and also down-regulation of the expression of ICAM-1 protein. As crocin converts into crocetin, so probably elicit the prodrug characteristics. In addition, Crocin had protective effects on endothelial cells. Crocin could decrease $\mathrm{CE}$ in macrophages and uptake of Ox-LDL, inhibiting the formation of foam cell, which would promote the initiation and progression of atherosclerosis. 
Crocin could inhibit the $\mathrm{Ca}(2+)$ elevation in smooth muscle cell, $\mathrm{Ca}(2+)$ is an important second messenger that regulates a variety of cellular processes, including smooth muscle cell proliferation and gene expression. Crocin exerted antiatherosclerotic effects through decreasing the level of Ox-LDL that plays an important role in the initiation and progression of atherosclerosis. ${ }^{21}$

\section{Effects on blood pressure}

The aqueous and alcoholic extracts of Crocus sativus petals showed a decrease in blood pressure in a dose dependent manner in anaesthetised rats, in isolated rat vas deferens and guinea pig ileum etc. where responses were initiated by electrical stimulation. This decrease in blood pressure was proposed to be mediated postsynaptically. ${ }^{20}$

\section{Effect on coronary artery disease}

Fifty milligrams of saffron dissolved in $100 \mathrm{ml}$ of milk was administered twice a day to human subjects, and the significant decrease in lipoprotein oxidation susceptibility in patients with coronary artery disease (CAD) indicates the potential of saffron as an antioxidant. ${ }^{25}$

\section{CONCLUSION}

In Unani System of Medicine, Arjun (Terminalia arjuna) and Zafran (Crocus sativus) are being used as cardioprotectives and cardiotonics since ages. These pharmacological studies on arjun and zafran substantiate the use of these drugs in the management of cardiovascular diseases.

\section{REFERENCES}

1. World Health Organization. The global burden of disease 2004 update.[www.who.int/healthinfo/global_burden_disease/2004 repor t_update] Accessed 2 July 2012. Available from: http://www.who.int

2. Reddy SK. Cardiovascular diseases in the developing countries: Dimensions, determinants, dynamics and directions for public health action. Public Health Nutrition 2002; 5 (1A): 231-37. http:// dx.doi.org/10.1079/PHN2001298 PMid:12027289

3. Reddy K. India wakes up to the threat of cardiovascular diseases. J. Am. Coll. Cardiol 2007; 50:1370-72. http://dx.doi.org/10.1016/j.jac c.2007.04.097 PMid:17903637

4. Ashish J, Jain T, Devasagayam TPA. Cardioprotective and other beneficial effects of some indian medicinal Plants. J Clin Biochem Nutr 2006; 38: 9-18. http://dx.doi.org/10.3164/jcbn.38.9

5. Mashour NH, Lin GI, Frishman WH. Herbal medicine for the treatment of cardiovascular disease. Arch Intern Med 1998; 158(9): 2226-34.

6. Vaidya ABD, Devasagayam TPA. Current status of herbal drugs in India: An Overview. J Clin Biochem Nutr 2007; 41: 1-11 http:/ dx.doi.org/10.3164/jcbn.2007001 PMid:18392106 PMCid:2274994

7. Husain A, Sofi GD, Tajuddin, Dang R, Kumar N. Unani system of medicine introduction and challenges. Medical Journal of Islamic World Academy of Sciences 2010; 18: 27-30.

8. Sina I. Al-Qanun fil-Tibb (English translation): Jamia Hamdard, New Delhi; 1993. p.32.

9. Kabir H. Introduction to Ilmul Advia 1st ed.: Shamsher Publisher; 2002. p. 42-9.
10. Anonymous. Terminalia arjuna (Monograph) Alternative Medicine Review: Volume 4, Number 6. p. 436-37. PMid: 10608917

11. Dwivedi S. Terminalia arjuna Wight \& Arn.-a useful drug for cardiovascular disorders. J. Ethnopharmacol 2007; 114: 114-129. http://dx.doi.org/10.1016/j.jep.2007.08.003 PMid:17875376

12. Parveen A, Babbar R, Agarwal S, Kotwani A, Fahim M. Mechanistic Clues in the cardioprotective effect of Terminalia Arjuna Bark Extract in isoproterenol-Induced chronic heart failure in rats. Cardiovasc Toxicol 2011; 11: 48-57. http://dx.doi.org/ 10.1007/s12012-010-9099-2 PMid:21116736

13. Ram A, Lauria P, Gupta R, Kumar P, Sharma VN. Hypocholesterolaemic effects of Terminalia arjuna tree bark. J Ethnopharmacol 1997; 55(3): 165-169. http://dx.doi.org/10.1016 /S0378-8741(96)01493-6

14. Gauthaman K, Maulik M, Kumari R. Effect of chronic treatment with bark of Terminalia arjuna: a study on the isolated reperfused rat heart. J Ethnopharmacol 2001; 75: 197- 201. http://dx.doi.org/ 10.1016/S0378-8741(01)00183-0

15. Karthikeyan K, Sarala Bai BR, Gauthaman K, Sathish KS, Devaraj SN. Cardioprotective effect of the alcoholic extract of Terminalia arjuna bark in an in vivo model of myocardial ischemic reperfusion injury. Life Sci 2003; 73: 2727-39. http://dx.doi.org/10.1016/S00243205(03)00671-4

16. Gauthaman K, Mohamed Saleem TS, Ravi V, Patel SS, Devaraj SN. Alcoholic Extract of Terminalia Arjuna Protects Rabbit Heart against Ischemic-Reperfusion Injury: Role of Antioxidant Enzymes and Heat Shock Protein WASET 2008; 42: 488-498.

17. Manna P, Sinha M, Sil PC. Aqueous extract of Terminalia arjuna prevents carbon tetrachloride induced hepatic and renal disorders. BMC Complement Altern Med 2006; 6: 33-44. http://dx.doi.org/ 10.1186/1472-6882-6-33 PMid:17010209 PMCid:1599753

18. Nammi S, Gudavalli R, Babu BS, Lodagala DS, Boini KM. Possible mechanism of hypotension produced by $70 \%$ alcoholic extract of Terminalia arjuna (L.) in anaesthetised dogs. BMC Complement Altern Med 2003; 3: 5-8. http://dx.doi.org/10.1186/1472-6882-3-5

19. Bharani A, Ganguli A, Mathur L, Jamra Y, Raman P. Efficacy of Terminalia arjuna in chronic stable angina: a double-blind, placebo controlled, crossover study comparing Terminalia arjuna with isosorbide mononitrate. Indian Heart Journal 2002; 54: 170-175. PMid: 12086380

20. Bhargava K V. Medicinal uses and pharmacological properties Of Crocus Sativus Linn (Saffron). Int J Pharm Pharm Sci 2011; 3 Suppl 3: 2226.

21. Singla RK, Bhat GV. Crocin: An Overview. Indo Global Journal of Pharmaceutical Sciences, 2011; 1Suppl 4: 281-286.

22. Kumar V, Bhat ZA, Kumar D, Khan NA, Chashoo IA, Shah MY Pharmacological profile of Crocus sativus. Pharmacologyonline 2011; 3: 799-811.

23. Goyal SN, Arora S, Sharma AK, Joshi S, Ray R, Bhatia J, et al Preventive effect of crocin of Crocus sativus on hemodynamic, biochemical, histopathological and ultrastructural alterations in isoproterenol-induced cardiotoxicity in rats. Phytomedicine 2010; 17: 227-232. http://dx.doi.org/10.1016/j.phymed.2009.08.009 PMid: 19747807

24. Jahanbakhsh Z, Rasoulian B, Jafari M, Shekarforoush S, Esmailidehaj M, Mohammadi MT, et al. Protective effect of crocin against reperfusion-induced cardiac arrhythmias in anaesthetized rat. EXCLI Journal 2012; 11: 20-29.

25. Srivastava R, Ahmed H, Dixit RK, Dharamveer, Saraf SA. Crocus sativus L.: A comprehensive review. Pharmacogn Rev 2010; 4 Suppl 8: 200-208. http://dx.doi.org/10.4103/0973-7847.70919 PMid:22228962 PMCid:3249922

\section{Cite this article as:}

Rabbani Syed Arman, Ali Syed Mahtab. Unani drugs in the management of cardiovascular diseases: A review on pharmacological studies on Arjun and Zafran. Int. J. Res. Ayurveda Pharm. 2013;4(3):463-467 